\title{
Research on the Development Strategies of E-Commerce Logistics of Agricultural Products in Heyuan
}

\author{
Chunyan Lv' \\ ${ }^{1}$ Management Department, Heyuan Vocational and Technical College, Heyuan City, Guangdong, \\ 517000, China \\ *E-mail: 14553346@qq.com
}

Keywords: E-commerce of agricultural product; Cold chain; Logistics

\begin{abstract}
With the popularity of the Internet and the support of the national strategy to take "targeted measures in poverty alleviation", the e-commerce of agricultural products in Heyuan has risen rapidly. However, the successful implementation of agricultural products e-commerce transactions cannot be achieved without supporting services of offline logistics. Innovating the e-commerce logistics mode of agricultural products and improving the efficiency of agricultural product distribution are the basis for the smooth development of agricultural products e-commerce. Based on the summary of the current situation of agricultural products e-commerce logistics in Heyuan, this paper analyzed the current problems in e-commerce logistics of agricultural products in Heyuan, and finally proposed the development strategies of e-commerce logistics of agricultural products in Heyuan based on the concept of supply-side structural reform.
\end{abstract}

\section{Introduction}

China is a big agricultural country, but the poor circulation of agricultural products has always been one of the important factors that hinder the sustainable development of rural economy and affect farmers' income. With the popularity of the Internet and the rapid rise of e-commerce, the e-commerce of agricultural products in China has developed rapidly. According to the big data monitored by the Ministry of Commerce, the online retail sales of agricultural products in whole China in the first three quarters of 2019 was 282.47 billion yuan, with a year-on-year increase of $26.4 \%$. At the same time, in order to promote the development of agriculture, the government has also made many favorable policies and regulations, including "Internet +", "Rural logistics", "Returning home to start a business", "Traceability of agricultural products", and "Digital village". In September, the National Development and Reform Commission issued the notice on supporting internet poverty alleviation project, which supported the "Internet + " agricultural products project, and built up a supply chain system, operation service system, logistics and warehousing support system to facilitate the online sale of agricultural product in poor areas. In addition, China's " Outline of Digital Rural Development Strategy" proposed to complete the building of digital villages by 2050, and support the rural areas to fully revitalize. It can be seen that the e-commerce market of agricultural products in China will have a booming development. However, it cannot be ignored that the current cost of e-commerce logistics of agricultural products in China is generally high and the technical level is low. Therefore, innovating e-commerce logistics modes for agricultural products and improving the efficiency of e-commerce logistics of agricultural products are the important guarantees to promote the sustainable development of agricultural products e-commerce.

\section{Status of the e-commerce logistics of agricultural products in Heyuan}

\subsection{The booming development of e-commerce of agricultural products in Heyuan}

Heyuan is a typical agricultural city in Guangdong with various types and large output of agricultural products. Under the key planning of the "Thirteenth Five-Year Plan", Heyuan vigorously promoted the development of modern agriculture and developed six leading industries such as high-quality grain and oil, distinctive fruits, green vegetables, ecological breeding, flowering trees and shrubs, and 
southern medicinal materials, which has formed an agricultural production base with distinctive agricultural products such as Xianhu green tea, Heping kiwi, Lianping chick peach, Zijin spring swet orange, Dongyuan chestnut, Dragon fruit and blueberry, etc. In recent years, Heyuan has taken the development of rural e-commerce as an important task to support poverty alleviation, rural revitalization and the rural economic development. It has actively introduced E-commerce platforms such as Jingdong and Alibaba to accelerate the construction of county, town and village e-commerce, guided and supported the healthy and steady development of the e-commerce business entities, and promoted the sale of agricultural products from rural areas to cities. According to statistics, the online retail sales of Heyuan in 2018 was about 830 million yuan, of which the retail sales of rural commerce was about 280 million yuan, with a year-on-year growth of $17.8 \%$. E-commerce service stations have been established in more than 400 villages and towns, and the number of agricultural products e-commerce enterprises has exceeded 2100. The e-commerce network of agricultural products has basically taken shape.

\subsection{The development status of e-commerce logistics of agricultural products in Heyuan}

At present, the domestic e-commerce logistics mode mainly includes self-built and self-operated logistics mode, the transportation mode of third-party logistics enterprises and mixed logistics mode. According to statistics, there are few agricultural product e-commerce enterprises in Heyuan that adopt self-built logistics mode currently, and most of them rely on third-party logistics. From the distribution of logistics outlets in Heyuan, they are mainly from SF, Shentong, Zhongtong, Yunda, Debon and other enterprises. Most agricultural products are transported mainly by road and rail and easily affected by the natural climate, which difficult to meet the timeliness requirements of agricultural products e-commerce, with a relatively high loss rate of goods. According to the relevant data from the China Cold Chain Logistics Committee, in 2018, deterioration and loss rates in circulation of fruits, vegetables, meat and aquatic products in China reached about $11 \%$, over $20 \%$, $8 \%$ and $10 \%$, respectively. In developed countries, the loss rates of fruits and vegetables are generally controlled below 5\%. Among them, because the whole industrial chain of agricultural products in the Unite State is supported by cold chain logistics, the loss rate of fruits and vegetables from field to table is only $1 \%-2 \%$.

\section{Problems in the e-commerce logistics of agricultural products in Heyuan}

\subsection{Slow development of cold chain logistics}

Since most of the agricultural products are fresh, cold chain circulation is required. As an important way to ensure the safety of agricultural products and improve the quality of agricultural products, cold chain logistics plays an important role in agricultural product logistics. According to the data from the China Cold Chain Logistics Committee, the total demand for cold chain logistics of agricultural products in China reached 182 million tons in 2018, and the top three were fruits (28\%), vegetables $(27 \%)$ and meat products $(18 \%)$. The cold chain circulation rate of fruits, vegetables, meat and aquatic products in China are only $5 \%, 15 \%$ and $23 \%$, respectively. Most fresh agricultural products are still circulated at room temperature, while the cold chain circulation rate of meat and poultry in developed countries in Europe and America has reached 100\%, and that of vegetables and fruits are also above 95\%. Compared with the first-tier cities of Beijing, Shanghai, Guangzhou and Shenzhen, the cold chain logistics industry in Heyuan started late, with a low popularity rate, outdated cold store equipment, and serious shortage of refrigerated transport vehicles, which could not meet the logistic transportation demand of agricultural products in the picking season. At present, the demand for cold chain logistics is strong, but due to the huge investment cost of cold chain facilities, most companies are cautious about the investment in cold chain logistics. The cold chain circulation rate and transportation rate are far less than those of first- and second-tier cities, which leads to the inability to transport some seasonal agricultural products and large losses. 


\subsection{High logistics cost of agricultural e-commerce}

Since there is no offline store rent and labor costs, agricultural products sold through e-commerce platforms have a price advantage. However, e-commerce logistics also faces difficulties in scattered customer distribution, small order quantity and high delivery frequency, which lead to high logistics costs. At present, the e-commerce logistics and distribution of agricultural products in Heyuan are usually undertaken by individual transportation owners, so there is no complete supply chain between the main bodies of each link. The integration of online and offline agricultural products is not strong, leading to a loose circulation of agricultural products. In the process of distribution, there are many problems such as high distribution frequency, various product categories, u non-standard product packaging, narrow distribution range and low distribution quality, which result in low efficiency of e-commerce distribution of agricultural products. The phenomenon of high distribution cost is common.

\subsection{Low level of logistics informatization}

Most logistics enterprises in China are still in the initial stage of informatization construction at present. The adopted information technology is mainly to meet the requirement of general business operation, while the actual application of new technology and new achievements is relatively slow. The technical equipment of automated and intelligent warehousing, transportation, carry that have been widely applied in the countries with developed logistics are not widely used in China's logistics enterprises. The application of technologies such as electronic data interchange (EDI), geographic information system (GIS), global positioning system (GPS) is very limited, and network technology is still at the primary level. Heyuan as a four-tier city is even more so, with a low informatization degree of most logistics enterprises, cannot keep up with the development and requirements of ecommerce of agricultural products. There are problems such as difficult collection and slow update of agricultural product information. In the whole chain of agricultural product picking, transportation, storage, packaging, circulation, processing and sales, product logistics and e-commerce information cannot be shared in real time, and there are often the phenomena that "the goods can't find the car" and "the car can't find the goods".

\section{Countermeasures for the development of e-commerce logistics of agricultural products in Heyuan}

\subsection{Improve the cold chain logistics service system for agricultural products e-commerce}

Establishing a sound cold chain logistics system for agricultural products can effectively promote the circulation of agricultural products and meet the increasingly diverse needs of consumers. Agricultural products e-commerce enterprises in Heyuan can obtain cold chain logistics capabilities through self-built logistics and third-party logistics. For strong enterprises, they can choose to build their own cold chain logistics. Although the input cost is high, it will be more in line with the actual needs, operational processes and rhythm of the enterprise. For some small and medium-sized enterprises, third-party logistics cold chain logistics can be used to reduce the costs of transportation logistics and achieve efficient utilization of resources. At present, domestic cold chain logistics include SF, Jingdong, Cai Niao cold chain, and Suning cold chain. The town government can invite these logistics enterprises to set up business in the town according to the sales of local agricultural products, ensuring the rapid circulation of the huge number of agricultural products to the destination.

\subsection{Improve the efficiency of e-commerce logistics of agricultural products}

Compared with ordinary commodity logistics, agricultural products e-commerce has more stringent requirements for the quality and efficiency of logistics service. The main reason why consumers choose online e-commerce to buy agricultural products instead of offline physical stores is that ecommerce has certain advantages in terms of price, service and efficiency. Therefore, if e-commerce of agricultural products wants to gain more market share, it is necessary to continuously innovate the agricultural products logistics model from the perspective of supply chain management, optimize the 
existing agricultural products logistics links, standardize the processing, packaging, inventory, distribution and other links of agricultural products, effectively improve the transportation efficiency of logistics, and reduce the logistics cost of agricultural products, to realize the competitive advantage of enterprises and the value added of consumers.

\subsection{Improve the level of logistics information and develop smart logistics}

First of all, in the context of big data, the development of e-commerce logistics of agricultural products must further strengthen the construction of agricultural products e-commerce logistics data platform, and improve the ability of information and data processing technology of agricultural products e-commerce logistics. Consumers should be regarded as the demand subjects and the supply chain as the direction, to develop block chain technology, establish large-scale big data group, and improve the logistics efficiency of agricultural products e-commerce.

Secondly, it needs to promotes the connection between agricultural products e-commerce and logistics resources, strengthen the construction of infrastructure networks, and support the construction of "e-commerce + logistics" parks, so that resources can be shared in real time to the greatest extent, and the organic integration of logistics and business flow is realized.

Finally, in the development of smart logistics, bar code, radio frequency identification, global positioning system, geographic information system and other information technologies can be popularized to gradually promote the monitoring and tracking of the whole process of goods trading, acceptance, transportation, warehousing and distribution, so as to improve the efficiency of logistics and transportation.

\section{Acknowledgment}

This research was financially supported by the Key Project of Humanities and Social Sciences of Heyuan Polytechnic (No. 2017_sk02)

\section{References}

[1] Hui Wang, Research on the strategy development of e-Commerce logistics of agricultural products in Hainan under the background of "Internet +", China Journal of Commerce, vol.24, pp.11-12, 2018.

[2] Man Huang and Bin Huang, Optimization mechanism and direction of e-commerce logistics service for fresh agricultural products, Journal of Minjiang University, vol.39, pp.32-40, 2018.

[3] Wei Liu, Analysis on the development of agricultural products e-commerce logistics in Anhui province under the background of big data, Journal of Tongling University, vol.17, pp.2630,2018 .

[4] Zhe Chen and Yi Deng, Research on e-commerce logistics distribution mode of fresh agricultural products, Journal of Commercial Economics, vol.14, pp.103-106,2018. 